\title{
An unusual association of pleural effusion with acute viral hepatitis $A$ infection
}

This article was published in the following Dove Press journal:

Pediatric Health, Medicine and Therapeutics

23 October 2014

Number of times this article has been viewed

\section{Ajaya Kumar Dhakal \\ Arati Shakya \\ Devendra Shrestha \\ Subhash Chandra Shah \\ Henish Shakya}

Department of Pediatrics, KIST

Medical College Teaching Hospital, Imadol, Lalitpur, Nepal
Correspondence: Ajaya Kumar Dhakal Department of Pediatrics, KIST Medical College Teaching Hospital, Imadol, Lalitpur, Nepal

Tel +977984 |3| 6649

Email ajayakdhakal@gmail.com

\begin{abstract}
Hepatitis A virus infection is a common public health problem in developing countries primarily due to poor hygiene and sanitation. The clinical features of hepatitis A virus are mostly related to the derangement of liver function with occasional extrahepatic complications. Herein, a 2.5-year-old girl presented with abdominal pain and decreased appetite for 4 days, high-colored urine for 3 days, and yellowish discoloration of the eyes for 2 days. On presentation, there was icterus along with hepatomegaly and diminished breath sounds on the right side were noted 1 day after admission. Chest X-ray revealed right sided pleural effusion; however, ultrasonography of chest and abdomen displayed bilateral pleural effusion (right more than left) and minimal ascites with thickened gall bladder wall. Immunoglobulin $\mathrm{M}$ anti-hepatitis-A virus serology was positive. The pleural effusion in this child resolved spontaneously in 10 days. We report this case to highlight that hepatitis A infection should be considered in the differential diagnosis of pleural effusion in a patient with features of acute hepatitis. However, other common causes of pleural effusion such as tuberculosis and parapneumonic effusions that may coexist with hepatitis, especially in developing world, need to be excluded.
\end{abstract}

Keywords: hepatitis A, pleural effusion, viral hepatitis

\section{Introduction}

Hepatitis due to hepatitis A virus (HAV) infection is a widespread illness in children in developing countries, owing exclusively to poor hygiene and sanitation. It is generally a benign and self-limiting disease requiring minimal supportive treatment. The clinical manifestations of HAV infections are usually localized to problems related to liver dysfunction, but occasionally are associated with atypical presentations including anasarca, ${ }^{1}$ isolated pleural effusion, ${ }^{2}$ pleural effusion and ascites, ${ }^{3}$ and a combination of pleural effusion, ascites, and acalculous cholecystitis. ${ }^{4}$ In this report, we describe a case of acute HAV infection with bilateral pleural effusion with minimal ascites in a child, which spontaneously resolved with supportive treatment.

\section{Case presentation}

A 2.5-year-old girl presented to the emergency department with upper abdominal pain and decreased appetite for 4 days, passage of high-colored urine for 3 days, and yellowish discoloration of the eyes for 2 days. There was no history of fever, bleeding, previous history of jaundice, blood transfusion, cough, difficulty in breathing, fast breathing, weight loss, rashes, or decreased urine output. The parents denied any 
contact history of tuberculosis. At admission, she was alert and active with a temperature of $36.7^{\circ} \mathrm{C}$. Her respiratory rate was 28 breaths per minute, pulse rate was 110 beats per minute, blood pressure was $100 / 70 \mathrm{mmHg}$, and oxygen saturation was $99 \%$ at room air. The weight and height were age appropriate. Positive findings on physical examination were icterus and soft, tender hepatomegaly with liver span of $10 \mathrm{~cm}$ at admission. Dullness on percussion with decreased breath sounds on the right axillary area of the chest developed on the first day of admission. The rest of the systemic examination was normal.

On laboratory investigation, hemoglobin was $102 \mathrm{~g} / \mathrm{L}$, total leukocyte count was $7.4 \times 10^{9} / \mathrm{L}$ with neutrophils $52 \%$ and lymphocytes $48 \%$, platelets count was $350 \times 10^{9} / \mathrm{L}$, and erythrocyte sedimentation rate was $32 \mathrm{~mm}$ at the end of 1 hour. Peripheral smear was normocytic and normochromic, with no atypical cells. Prothrombin time was 14 seconds with an international normalized ratio of 1 . Total bilirubin was $99.1 \mu \mathrm{mol} / \mathrm{L}$ with direct fraction of $78.6 \mu \mathrm{mol} / \mathrm{L}$, while aspartate aminotransferase was 1,590 U/L, alanine aminotransferase was $1,735 \mathrm{U} / \mathrm{L}$, and alkaline phosphatase was $1,434 \mathrm{U} / \mathrm{L}$. Serum total protein was $71 \mathrm{~g} / \mathrm{L}$ and serum lactate dehydrogenase (LDH) was $914 \mathrm{U} / \mathrm{L}$. Urine routine microscopy was normal. Ultrasonography revealed thickened gall bladder wall, minimal ascites, and bilateral pleural effusion (right more than left). Chest X-ray showed large right sided pleural effusion (Figure 1). Pleural fluid analysis showed total count of $2,000 / \mu \mathrm{L}$ with polymorphs $5 \%$ and

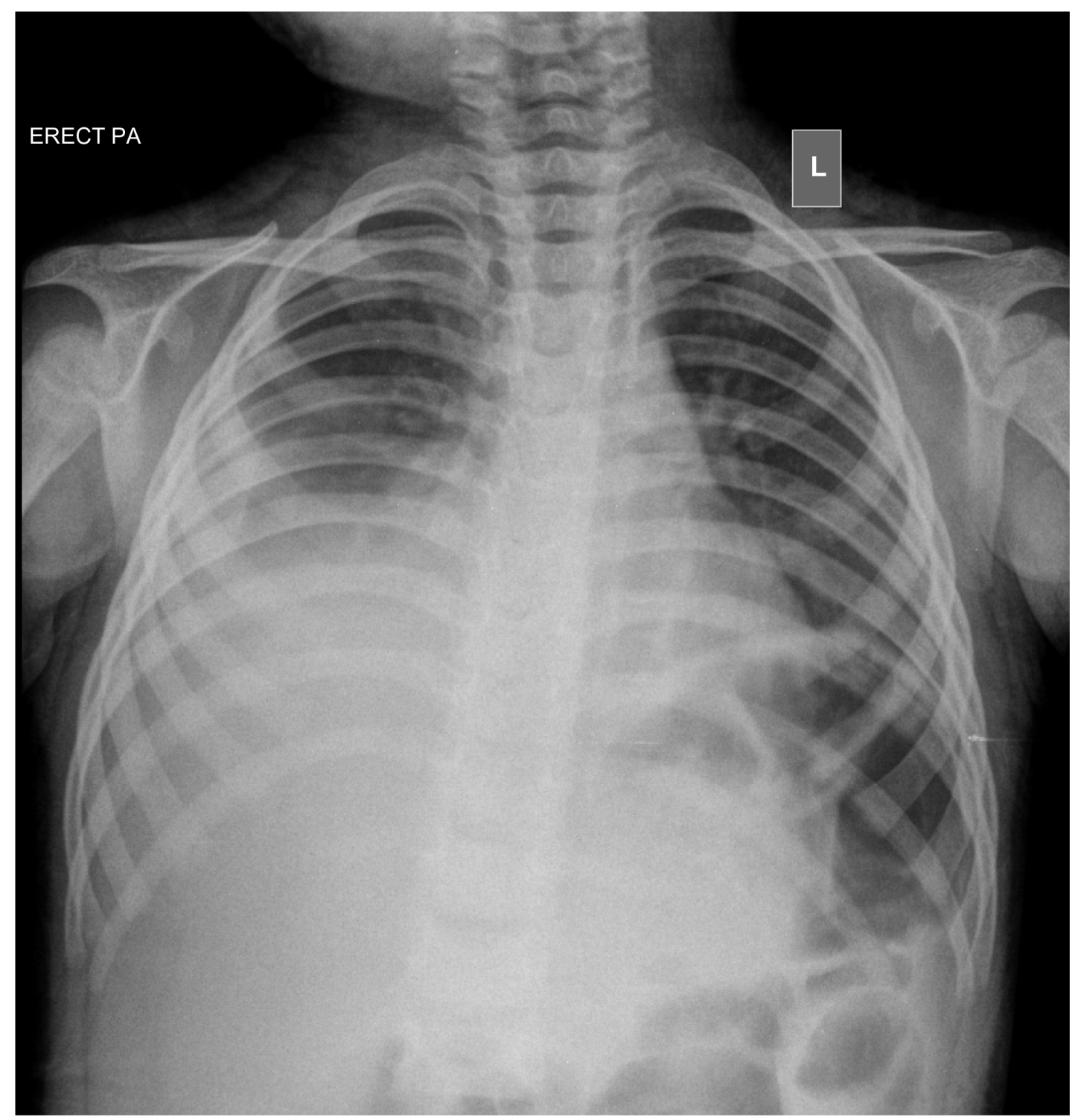

Figure I Chest X-ray PA view showing right sided pleural effusion. Abbreviations: PA, posteroanterior; L, left. 
lymphocytes $95 \%$, glucose $89 \mathrm{mg} / \mathrm{dL}$, total protein $3.5 \mathrm{~g} / \mathrm{dL}$, LDH 434 U/L, and adenosine deaminase 28 U/L. Gram stain of pleural fluid did not reveal any organism and pleural fluid culture was sterile. An acid fast bacillus staining of pleural fluid was negative. Mantoux test reading at 72 hours revealed no induration. Immunoglobulin $\mathrm{M}$ anti-HAV serology was positive, but hepatitis B, hepatitis C, and Leptospira serology were negative.

She was initially started with lactulose, antacids, and intravenous fluids. An intravenous antibiotic was started for the persistent fever that appeared after 24 hours of admission, in view of the possibility of concomitant bacterial infection. The child was discharged 6 days after hospital admission with the diagnosis of acute viral hepatitis A infection with bilateral pleural effusion. On follow-up 5 days after discharge, liver function tests were near normal and there were no features of pleural effusion on either chest X-ray (Figure 2) or chest ultrasonography.

\section{Discussion}

Acute HAV infection is usually a benign, self-limiting infection with symptoms mainly pertaining to liver derangement. Pleural effusion associated with hepatitis A infection is a rare extrahepatic complication in children. ${ }^{5}$ Pleural effusions have been documented mostly on the right side in patients with hepatitis A infection, ${ }^{2,6,7}$ however, bilateral effusion has also been reported. ${ }^{3}$ Even consolidation in chest X-ray along with pleural effusion in association with HAV infection has been previously

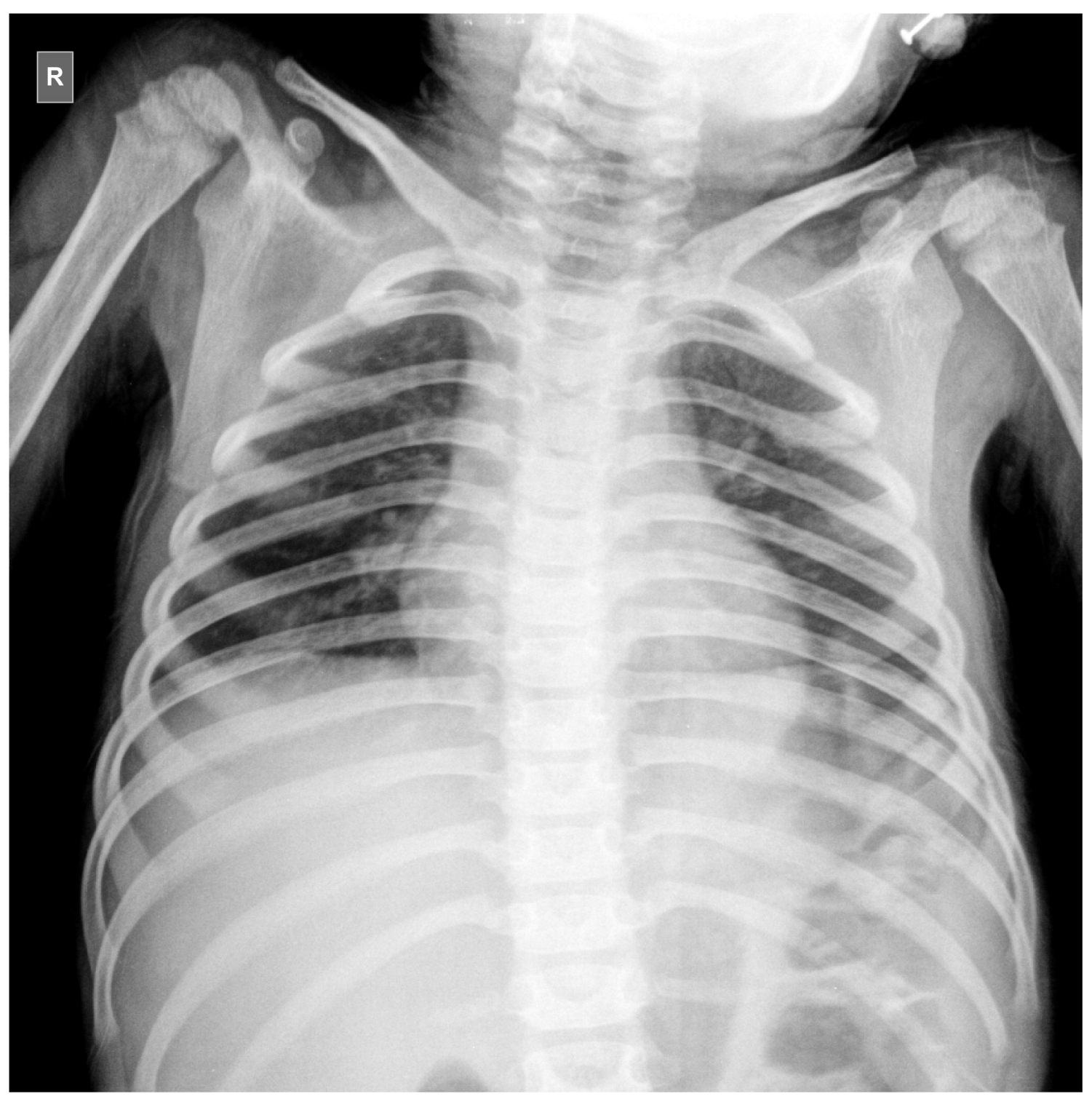

Figure 2 Chest $\mathrm{X}$-ray PA view showing resolved effusion in the follow-up. Abbreviations: $P A$, posteroanterior; $R$, right. 
reported. ${ }^{2,6}$ Although the exact incidence is unknown, a total of 15 documented cases (eight in adults and seven in children) of pleural effusion associated with hepatitis A infection have been described in the literature until recently. ${ }^{5}$ The precise mechanism of pleural effusion in hepatitis A infection is unknown and may be multifactorial. One of the postulated mechanisms is the transport of fluid from diaphragmatic lymphatics or leakage from a diaphragmatic defect to the pleural cavity from coexistent ascites. ${ }^{3}$ Another potential mechanism is a virus-induced inflammation of the liver, which through unknown mechanisms leads to effusion. ${ }^{6}$ Pleural effusion may also develop as a result of immune complex deposition ${ }^{4}$ or direct effect of viral invasion on pleura. ${ }^{8}$ Similarly, ascites may occur as a result of venous and lymphatic obstruction or decreased oncotic pressure due to hypoalbuminemia. ${ }^{3}$ The pleural effusion due to HAV infection does not require any treatment and is thought to be a benign early complication. HAV-associated pleural effusion resolves spontaneously even though liver pathology deteriorates. ${ }^{7}$ The presence of pleural effusion or ascites in a patient with HAV infection does not indicate an "unfavorable" outcome. ${ }^{3}$

Ultrasound-guided thoracocentesis was performed to determine the etiology of pleural effusion in this child. The pleural fluid analysis demonstrated an exudative type of pleural effusion based on high pleural fluid protein content (3.5 g/dL) and high pleural fluid LDH level (434 IU/L) with a cell count of $2,000 / \mu \mathrm{L}$ with lymphocytic predominance. The most common causes of the exudative pleural effusion in developing countries are tuberculosis and parapneumonic effusion which may coexist with other medical illnesses. Pneumonia was considered less likely as the child did not have a history of cough, fast breathing, or any signs of respiratory distress. There was also no evidence of radiographic parenchymal involvement and the pleural effusion was bilateral. Exudative pleural effusion with lymphocyte predominance is also unusual in pneumonia. The published literature also suggests that parapneumonic pleural effusion is unlikely in the presence of lymphocytosis in an exudative pleural effusion. ${ }^{9}$ Tuberculosis was ruled out due to the short duration of the illness, absence of contact history, and negative microbiological culture and staining results of pleural fluids. Clinical features and laboratory analysis for other causes of pleural effusion were also negative. Hence, the diagnosis of acute viral hepatitis $\mathrm{A}$ infection with associated pleural effusion was made.

Pleural fluid glucose and protein levels in our patient were almost similar to previous reports with acute HAV-associated pleural effusion. ${ }^{6}$ However, in contrast to previous studies, ${ }^{4,6,7}$ this patient had a cell count of $2,000 / \mu \mathrm{L}$ with lymphocytic predominance in the pleural fluid and both exudative and transudative types of pleural effusion have been described in patients with HAV infection. ${ }^{10}$ However, thoracocentesis is not recommended currently in evaluation of pleural effusion due to HAV infection in developed countries because of spontaneous resolutions of effusion and associated chronic infections are rare. ${ }^{11}$ Laboratory investigation to test for Epstein-Barr virus, Cytomegalovirus, and Rickettsial disease in these clinical scenarios is recommended. ${ }^{4}$ Unfortunately, these tests were not performed due to lack of availability and clinical recovery of patient.

\section{Conclusion}

This case report highlights that pleural effusion can be associated with HAV infection and that in a child with jaundice and pleural effusion, hepatitis A infection should be strongly considered. Pleural effusion associated with hepatitis A infection is benign and self-limiting and does not require any therapeutic intervention apart from a good supportive therapy.

\section{Disclosure}

The authors report no conflicts of interest in this work.

\section{References}

1. Saha S, Sengupta M. Anasarca-an atypical presentation of hepatitis A. Eastern J Med. 2012;17(3):133-134.

2. Bukulmez A, Koken R, Melek H, Dogru O, Ovali F. Pleural effusion: a rare complication of hepatitis A. Indian J Med Microbiol. 2008;26(1):87-88.

3. Gürkan F. Ascites and pleural effusion accompanying hepatitis A infection in a child. Clin Microbiol Infect. 2000;6(5):286-287.

4. Erdem E, Urganci N, Ceylan Y, Kara N, Ozcelik G, Gulec SG. Hepatitis a with pleural effusion, ascites and acalculous cholecystitis. Iran $J$ Pediatr. 2010;20(4):479-482.

5. Ponnurangam Nagarajan V, Palaniyadi A, Sathyamoorthi M, et al. Pleural effusion - An unusual cause. Australas Med J. 2012;5(7): 369-372.

6. Alhan E, Yildizdaş D, Yapicioğlu H, Necmi A. Pleural effusion associated with acute hepatitis A infection. Pediatr Infect Dis J. 1999;18(12):1111-1112.

7. Tesovic G, Vukelić D, Vuković B, Benić B, Bozinović D. Pleural effusion associated with acute hepatitis A infection. Pediatr Infect Dis $J$. 2000;19(6):585-586.

8. Kurt AN, Bulut Y, Turgut M, et al. Pleural effusion associated with hepatitis A. J Pediatr Inf. 2008;2:25-26.

9. Light RW. Parapneumonic effusions and empyema. Proc Am Thorac Soc. 2006;3(1):75-80.

10. Ko YS, Yoo KD, Hyun YS, et al. [A case of pleural effusion associated with acute hepatitis A]. Korean J Gastroenterol. 2010;55(3):198-202. Korean.

11. Kumar M, Kumar V, Tomar R. Hepatitis A with pleural effusion: a rare association. Ann Trop Paediatr. 2009;29(4):317-319. 
Pediatric Health, Medicine and Therapeutics

Dovepress

\section{Publish your work in this journal}

Pediatric Health, Medicine and Therapeutics is an international, peerreviewed, open access journal publishing original research, reports, editorials, reviews and commentaries. All aspects of health maintenance, preventative measures and disease treatment interventions are addressed within the journal. Practitioners from all disciplines are invited to submit their work as well as healthcare researchers and patient support groups. The manuscript management system is completely online and includes a very quick and fair peer-review system. Visit http://www.dovepress.com/ testimonials.php to read real quotes from published authors.

Submit your manuscript here: http://www.dovepress.com/pediatric-health-medicine-and-therapeutics-journal 